\title{
Pavement Guide Marks Recognition based on Projection
}

\author{
Yi WEI ${ }^{1, *}$, Hang YANG $^{1}$, Chenhui YANG ${ }^{1}$, Yamin $\mathrm{XU}^{2}$ \\ ${ }^{1}$ School of Automation \\ Wuhan University of Technology \\ 122 Luoshi Road, Wuhan, PR China \\ ${ }^{2}$ School of Geodesy and Geomatics \\ Wuhan University \\ 129 Luoyu Road, Wuhan, PR China

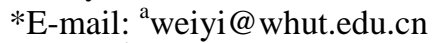 \\ E-mail: b648719145@qq.com \\ E-mail: c270917365@qq.com

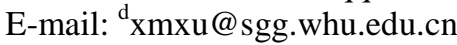

\begin{abstract}
With the development of intelligent transportation system, the automatic recognition of pavement guide marks has attracted more and more attention. Due to their convexity-concavity in shape, existing algorithms can hardly complete the task. This paper introduces projection technique that transforming the $2 \mathrm{D}$ irregular shapes into two 1D signals. By conducting the signal similarity measurement, guide marks recognition is achieved with higher accuracy and faster speed. Experimental results also demonstrate its potential in some real-time applications.
\end{abstract}

Keywords-guide marks recognition; projection signal; signal similarity evaluation.

\section{INTRODUCTION}

Shape recognition, especially irregular shape recognition is one of the most widely studied subjects in the image understanding areas. With the development of Intelligent Transportation System, the recognition of pavement guide marks has become more and more popular. In a common sense, guide marks are well defined but with both convex and concave points along their borders. Thus the representation and corresponding recognition methods are facing tough problems.

This paper adopts projection technique and transforms a 2D shape into two 1D projection signals. Dimension reduction is completed and convexity-concavity problems are therefore avoided, all through the projection of a binary image in horizontal and vertical directions. Then a similarity evaluation algorithm is introduced to measure how close projection signals of a tested shape and the reference are in each direction. Conclusions are made based on the similarity of whether the unknown shape is one of the guide marks

All experiments are run in natural scenes with different sorts of real pavement status. The results show the work has its potential in irregular shape recognition towards real-time applications.

\section{PROJECTION TECHNIQUE}

In image understanding field, features representing a specific class of shape and the corresponding feature extraction technique are two key parts in the overall shape recognition process. From the pattern recognition point of view, feature extraction is a transform that switch a set of data in an $\mathrm{N}$ dimensional space into that of an $\mathrm{M}$ dimensional space, where there is $\mathrm{M}<\mathrm{N}$. It is also a redundancy reduction while only a few features required for the pattern classification are kept. Projection of a binary image in a given direction is a such transform. After the projection in both horizontal and vertical directions, a $2 \mathrm{D}$ image becomes two $1 \mathrm{D}$ signals.

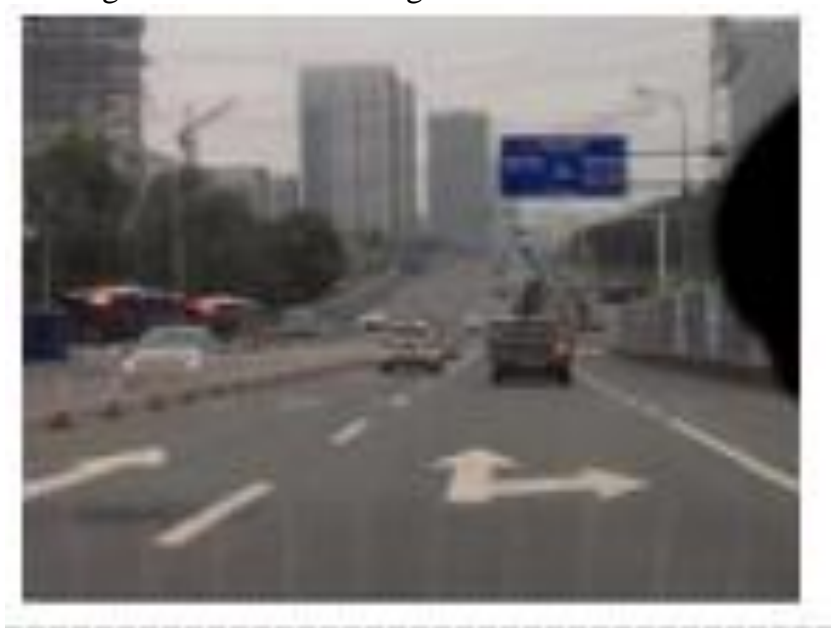

a) Original image of a guide mark

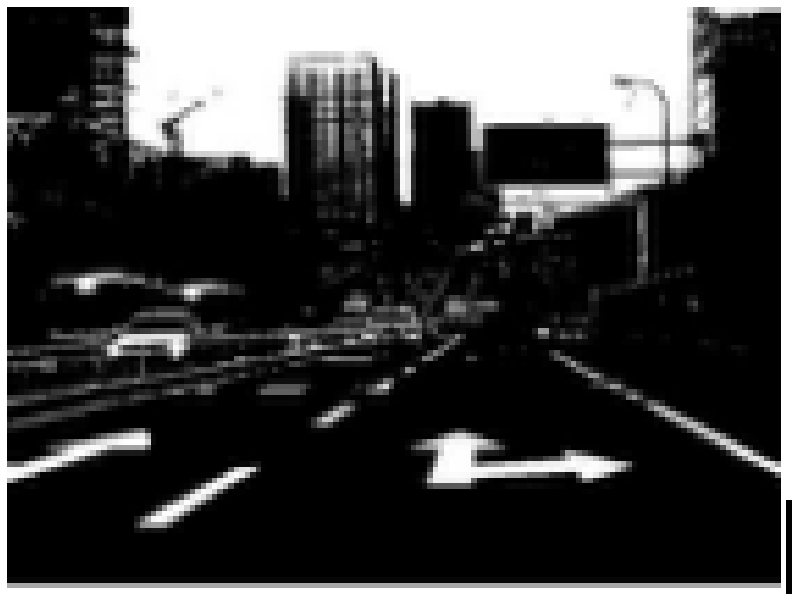

b) Binary image of the guide mark 


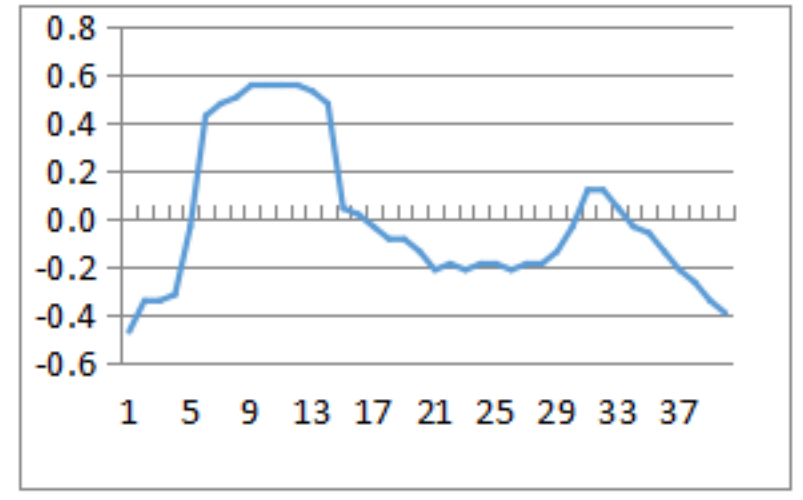

c) Projection onto the $\mathrm{X}$ axis $\mathrm{Hp}_{\mathrm{k}}(\mathrm{x})$

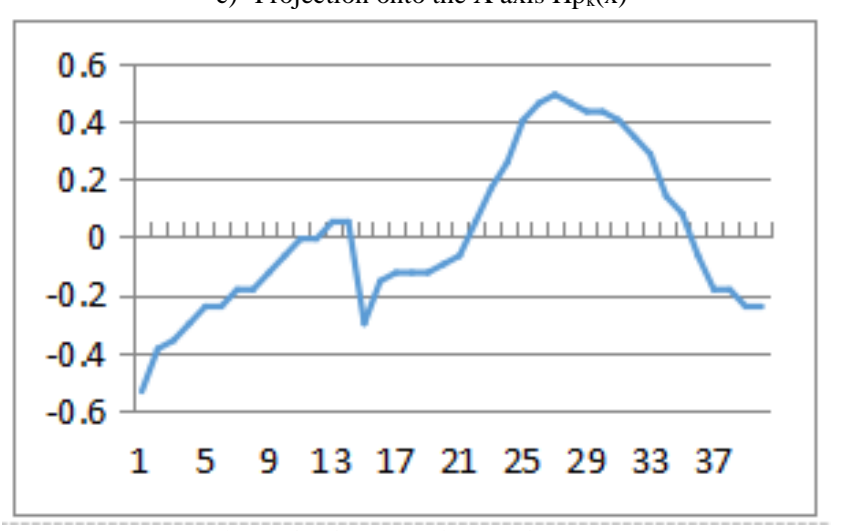

d) Projection onto the $\mathrm{Y}$ axis $\mathrm{Vp}_{\mathrm{k}}(\mathrm{y})$

Figure 1. Pavement guide mark and its projection signals

Given a $\mathrm{h} \times \mathrm{w}$ binary image contains a straight and right turn guide mark as shown in Fig 1(b), it can be represented as

$$
\mathrm{B}(\mathrm{x}, \mathrm{y})=\left\{\begin{array}{l}
1, \text { foreground } \\
0, \text { background }
\end{array}\right.
$$

The projection of $\mathrm{B}(\mathrm{x}, \mathrm{y})$ onto the $\mathrm{X}$ axis is defined as $h p(x)$, and the projection of $B(x, y)$ onto the $Y$ axis is defined as $v p(y)$

$$
\left\{\begin{array}{l}
h p(x)=\sum_{y=1}^{h} B(x, y) \\
\operatorname{vp}(y)=\sum_{x=1}^{w} B(x, y)
\end{array}\right.
$$

From (2), $\mathrm{hp}(\mathrm{x})$ is the accumulation of all foreground in each column and $\operatorname{vp}(\mathrm{y})$ is the sum of white pixels in each row.

In order to calculate the similarity between a tested signal and the reference, some normalizations must be taken in advance and they mainly include two parts:

(1)Signal scaling: As can be seen from (2), the lengths of two original projection signals are not invariant to the size of the image. Thus they have to conduct scaling or resize to a predefined length. Here suppose $\mathrm{k}$ is the new length of two projection signals and $h p(x)$ and $\operatorname{vp}(y)$ becomes $\mathrm{hp}_{\mathrm{k}}(\mathrm{x})$ and $\mathrm{vp}_{\mathrm{k}}(\mathrm{y})$ respectively.

(2)Magnitude normalization: The magnitude of $\mathrm{hp}_{\mathrm{k}}(\mathrm{x})$ and $\operatorname{vp}_{\mathrm{k}}(\mathrm{y})$ are rescaled and shifted within $0 \sim 1$ through the following procedure

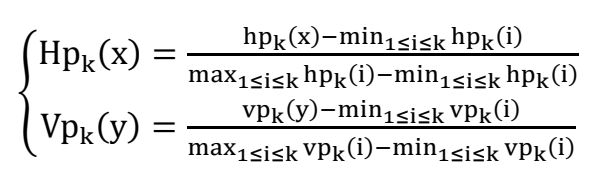

\section{ALGORITHM DESIGN}

Given a set of original color images obtained from the camera mounted on the front glass of a driving vehicle, image preprocessing techniques are firstly applied to calculate the binary images. Based on the projection introduced above, (2) and (3) are conducted simultaneously to obtain two normalized projection signals of each unknown shape. Signal similarity evaluation algorithm is then used to compare how close two projection signals are to its counterpart of the reference guide marks. Finally the shape recognition is completed based on the similarities.

In general, distances and correlation coefficients are two classes of the most commonly used similarity measurements. This paper adopts the definition of centroid in Physics to compare whether two signals are alike. Detailed explanation of a signal centroid can be found in [4], and it is directly used as follows.

Suppose the centroid of $\mathrm{Hp}_{\mathrm{k}}(\mathrm{x})$ is $\mathrm{H}_{\mathrm{c}}\left(\mathrm{x}_{\mathrm{hc}}, \mathrm{y}_{\mathrm{hc}}\right)$, and $\mathrm{V}_{\mathrm{c}}\left(\mathrm{x}_{\mathrm{vc}}, \mathrm{y}_{\mathrm{vc}}\right)$ is the centroid of $\mathrm{Vp}_{\mathrm{k}}(\mathrm{y})$. There are

$$
\left\{\begin{aligned}
\mathrm{x}_{\mathrm{hc}} & =\frac{\sum_{\mathrm{i}=1}^{\mathrm{k}} \mathrm{i} \times \mathrm{Hp}_{\mathrm{k}}{ }^{2}(\mathrm{i})}{\left.\sum_{\mathrm{i}=1}^{\mathrm{k}} \mathrm{Hp}_{\mathrm{k}}{ }^{2} \mathrm{i}\right)} \\
\mathrm{y}_{\mathrm{hc}} & =\frac{\sum_{\mathrm{i}=1}^{\mathrm{k}} \mathrm{Hp}_{\mathrm{k}}{ }^{3}(\mathrm{i})}{\sum_{\mathrm{i}=1}^{\mathrm{k}} \mathrm{Hp}_{\mathrm{k}}{ }^{2}(\mathrm{i})}
\end{aligned}\right.
$$

and

$$
\left\{\begin{aligned}
\mathrm{x}_{\mathrm{vc}} & =\frac{\sum_{\mathrm{i}=1}^{\mathrm{k}} \mathrm{i} \times \mathrm{Vp}_{\mathrm{k}}{ }^{2}(\mathrm{i})}{\sum_{\mathrm{i}=1}^{\mathrm{k}} \mathrm{Vp}_{\mathrm{k}}{ }^{2}(\mathrm{i})} \\
\mathrm{y}_{\mathrm{vc}} & =\frac{\sum_{\mathrm{i}=1}^{\mathrm{k}} \mathrm{Vp}_{\mathrm{k}}{ }^{3}(\mathrm{i})}{\sum_{\mathrm{i}=1}^{\mathrm{k}} \mathrm{Vp}_{\mathrm{k}}{ }^{2}(\mathrm{i})}
\end{aligned}\right.
$$

Both centroids of two projection signals of an unknown shape and a reference are compared respectively based on the Euclidean distance and the similarity between two shapes is written as

$$
\left\{\begin{array}{l}
\operatorname{Sim}_{\mathrm{H}}=\sqrt{\left(\mathrm{x}_{\mathrm{hc}}-\mathrm{x}_{\mathrm{hc}}{ }^{\prime}\right)^{2}+\left(\mathrm{y}_{\mathrm{hc}}-\mathrm{y}_{\mathrm{hc}}{ }^{\prime}\right)^{2}} \\
\operatorname{Sim}_{\mathrm{V}}=\sqrt{\left(\mathrm{x}_{\mathrm{vc}}-\mathrm{x}_{\mathrm{vc}}{ }^{\prime}\right)^{2}+\left(\mathrm{y}_{\mathrm{vc}}-\mathrm{y}_{\mathrm{vc}}\right)^{2}}
\end{array}\right.
$$

Where $\left(\mathrm{x}_{\mathrm{hc}}, \mathrm{y}_{\mathrm{hc}}\right)$ and $\left(\mathrm{x}_{\mathrm{vc}}, \mathrm{y}_{\mathrm{vc}}\right)$ correspond to the unknown shape, and $\left(\mathrm{x}_{\mathrm{hc}}, \mathrm{y}_{\mathrm{hc}}\right)^{\prime}$ and $\left(\mathrm{x}_{\mathrm{vc}}{ }^{\prime}, \mathrm{y}_{\mathrm{vc}}{ }^{\prime}\right)$ correspond to the reference shape.

If $\operatorname{Sim}_{\mathrm{H}}$ and $\mathrm{Sim}_{\mathrm{V}}$ reach the minimum with respect to the same reference, the unknown shape is then determined. Otherwise, further calculation

$$
\operatorname{Sim}=\sqrt{\operatorname{Sim}_{\mathrm{H}}^{2}+\operatorname{Sim}_{\mathrm{V}}^{2}}
$$

is conducted to make the decision. 


\section{EXPERIMENTAL RESULTS}

This paper chooses 9 common pavement guide marks as reference database. Each unknown shape is compared with all references in the database and the minimum value of $\operatorname{Sim}_{\mathrm{H}}$ and $\mathrm{Sim}_{\mathrm{V}}$ or Sim points out the result.

Four tested images are given in Fig. 2 and Table. 1 is the similarity evaluation of those 4 with respect to 9 references.
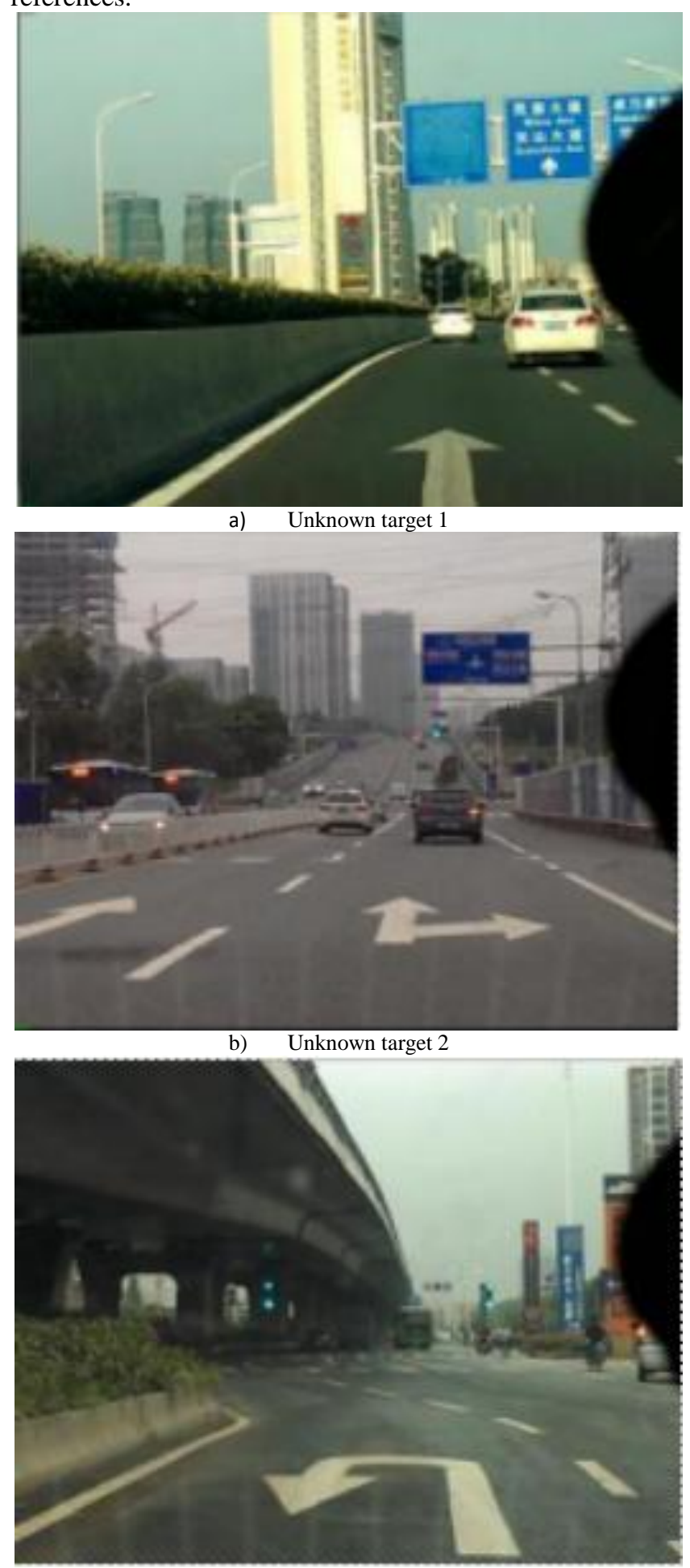

c) Unknown target 3

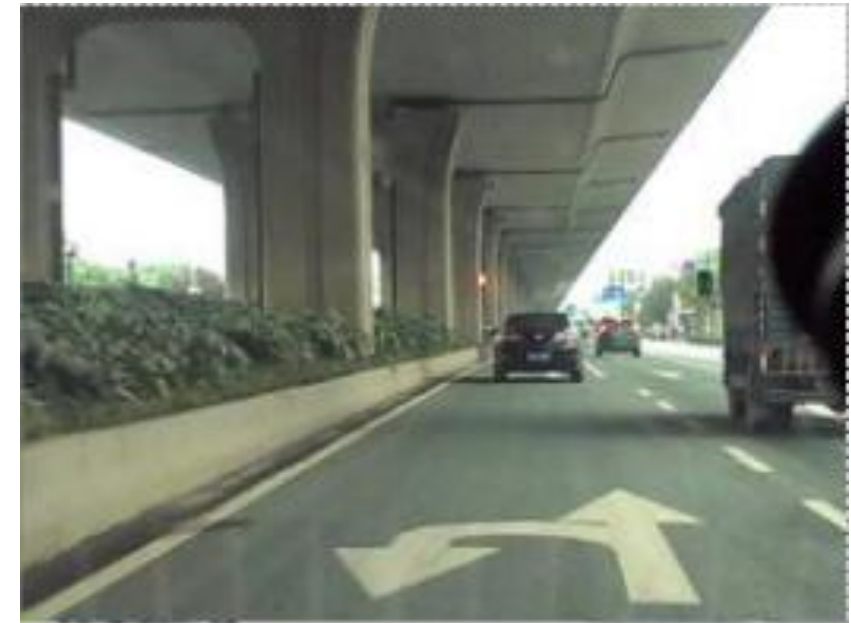

d) Unknown target 4

Figure 2. A group of unknown targets

TABLE I. SIMILARITY EVALUATION OF 4 UNKNOWN TARGETS WITH RESPECT TO REFERENCES

\begin{tabular}{|c|c|c|c|c|c|c|c|c|}
\hline \multirow{2}{*}{$\begin{array}{l}\text { Target } \\
\text { referencess }\end{array}$} & \multicolumn{2}{|c|}{ Target 1} & \multicolumn{2}{|c|}{ Target 2} & \multicolumn{2}{|c|}{ Target 3} & \multicolumn{2}{|c|}{ Target 4} \\
\hline & $\operatorname{Sim}_{H}$ & $\operatorname{Sim}_{V}$ & $\operatorname{Sim}_{\mathrm{H}}$ & $\operatorname{Sim}_{V}$ & $\operatorname{Sim}_{H}$ & $\operatorname{Sim}_{V}$ & $\operatorname{Sim}_{H}$ & $\operatorname{Sim}_{\mathrm{V}}$ \\
\hline & 2.02 & 1.65 & 12.17 & 2.32 & 19.45 & 2.53 & 21.70 & 3.08 \\
\hline & 8.67 & 3.72 & 6.80 & 3.32 & 4.57 & 2.38 & 5.14 & 3.73 \\
\hline & 8.56 & 2.74 & 6.52 & 2.77 & 3.66 & 2.44 & 3.85 & 2.69 \\
\hline & 7.66 & 2.96 & 4.37 & 2.06 & 7.24 & 4.05 & 7.73 & 2.12 \\
\hline & 7.84 & 3.10 & 2.11 & 0.46 & 10.03 & 5.19 & 10.89 & 2.97 \\
\hline & 5.35 & 3.13 & 7.83 & 3.12 & 10.53 & 2.53 & 11.26 & 3.44 \\
\hline & 8.96 & 3.20 & 7.05 & 1.92 & 3.21 & 4.25 & 1.93 & 0.81 \\
\hline & 8.78 & 2.73 & 3.92 & 2.80 & 9.19 & 2.45 & 9.85 & 2.82 \\
\hline & 7.48 & 3.11 & 7.41 & 0.75 & 5.65 & 5.29 & 6.02 & 3.20 \\
\hline
\end{tabular}

It can be seen from Table.1, unknown target 1,2 and 4 can find their match through (6), and unknown target 3 may use (7) to get the correct answer.

Large number of experiments have been run and all tested images are from real driving scenes. Results have demonstrated its recognition potential in both accuracy and speed.

\section{V.CONCLUSIONS}

Irregular shape recognition has been one of the most difficult tasks in the image understanding area. It becomes tougher when dealing with convex-concave shapes. This work introduces projection and transforms a 2D shape into two 1D signals. Then the signal similarity evaluation system is applied to measure how close the unknown shape is to the references. Experimental results have proven its advantages in pavement guide marks recognition and the proposed algorithm may be used in other shape recognition applications as well. 


\section{ACKNOWLEDGEMENT}

This research was financially supported by the National Science Foundation 41474005.

\section{REFERENCES}

[1] Wu Xiaojun, Zou Guanghua. High performance template matching algorithm based on edge geometric features [J]. Chinese Journal of scientific instrument, 2013, 34 (7): 1462-1469.

[2] Tan Feigang, Liu Weiming, Huang Ling, et al. Target re-recognition algorithm based on weighted Euclidean distance [J]. Journal of South China University of Technology (NATURAL SCIENCE EDITION). 2015 (9): 88-94.

[3] Zhang Chuang, Wang Tingting, et al., et al. Image edge detection based on Euclidean distance map [J]. Journal of image and graphics, 2013, 18 (2): 176-183.

[4] Cao qingjuan and Wang yongjun, Similarity search of time series based on centroid, Journal of Chongqing Institute of Science and Technology, 2010,12(5):142-145

[5] Ismail M F, Jaafar T R, Pin N C, et al. Sobel operator for edges detection in surface texture analysis[J]. 2015.

[6] Wan Jine, Yuan Baoshe, Gu Chao, et al. Recognition algorithm based on character normalization and double projection correlation [J]. computer applications. 2013, 33 (3): 645-647.

[7] Shi S, Mingb Y U, Honglic Y U, et al. SIFT Image Matching Algorithm Based on Similarity Measure Optimization[J]. Video Engineering. 2013. 